Este artigo trata de pesquisar a função de registro da tatuagem, passando pelas determinaçôes simbólicas, imaginárias e reais. Toma sua vertente de recorte pulsional, bem como a determinação de uma escrita corporal e a singularidade de um traço ao olhar do outro. Aborda tanto a função genérica, nas diferentes culturas, quanto a característica que assume na adolescência. Tatuagem; escrita; traço simbólico

MAKING "HIMSELF"

TATTOO: TRACE

AND WRITING IN

THE BODY BOARDS

This article treats

the research of the

function of the tattoo, in his determinations symbolical, imaginary and real. Takes the instinct body boards, as well as a body. writing determination and the trace of other looking. Treats the generality function of tattoo, in the cultural singularity, as well as the particularity of his meaning in the adolescence.

Tatto; writing; symbolical trace

\section{"SE FAZER" \\ TATUAR: TRAÇO \\ E ESCRITA DAS \\ BORDAS \\ CORPORAIS}

Ana Maria Medeiros da Costa ão é simples abordar a função que ocupa a tatuagem e não podemos resumi-la ao contexto atual. Veremos como essas marcas, que parecem compor uma questão estética secundária, ocupam um lugar importante no rol dos suportes corporais. Seu uso é bastante antigo, havendo indícios dessa prática desde os alvores da humanidade. Pode-se arriscar a dizer que seu surgimento esteja ligado à necessidade de produção de traços no real: seja nos ossos da caça (extensamente abordado por produções lacanianas a respeito do traço unário), seja para marcar uma pertença ao próprio corpo. Tatuar não é somente pintar-se, é também escarificar: introduzir pigmentos na derme compondo uma marca definitiva. Essa marca tem uma dupla função: tanto de coletivizar, como de singularizar.

Existem indícios de homens tatuados milênios antes de Cristo, sendo um costume extremamente

Psicanalista, membro da Associação Psicanalítica de Porto Alegre, Doutora em Psicologia Clínica - PUC-SP, Pós-doutoranda na Universidade de Paris 13. 


\section{Dossiê}

usado em muitas sociedades. O aparente desaparecimento (pelo menos uma retração no seu uso) deveu-se a uma proibição religiosa, abrangendo católicos e judeus. Essas religiões proibiram a tatuagem, porque a associaram a uma manifestação de ritual pagão. Como o paganismo foi banido pela religião monoteísta, foi proibido tudo o que dissesse respeito à tatuagem. Pode-se entender também a perseguição a essa prática porque tudo o que dizia respeito à exibição do corpo - no monoteísmo - foi recalcado. Tudo o que evidenciasse alguma espécie de erotização foi recalcado. Hoje, a herdeira desse recalque é a ciência. Aparentemente, teríamos uma espécie de supererotização do corpo. No entanto, aquilo que tem vigência é uma representação de corpos sem falhas, logo, sem bordas.

A tatuagem, como escarificação, é uma forma de fazer bordas corporais. De alguma maneira pareceria que, ao longo da história do homem, fosse sempre necessária a reconstituição, o recorte insistente, das bordas do corpo. Esse recorte tem a ver com a erotização e com o funcionamento pulsional, que dá suporte à erotização. As bordas constituem a nossa relação com o ambiente, com o outro e com a realidade. De bordas constitui-se o nosso olhar - são as bordas que fazem com que possamos ver. Ou seja, ter essa imagem que vem de fora e registramos como nossa.

Apesar de já nascermos com essas bordas e com a capacidade de que elas funcionem, sua atividade não se dá de forma natural. Por não funcionarem de forma natural, elas precisam ser recortadas. Essa necessidade não diz respeito a um mau funcionamento, senão que respondem à nossa condição de desnaturação, de determinações heterogêneas - simbólicas/imaginárias/reais. Como não funcionamos de forma natural, precisamos, constantemente, reconstituir os suportes corporais. Isso acontece privilegiadamente quando mudamos de lugar: na passagem da adolescência, por exemplo, ou outro tipo de mudança na vida, quando perdemos os referentes que amparam nosso corpo. Essa reconstituição das bordas corporais é o que dá suporte à circulação do nosso corpo, para nos sentirmos representados, apoiados e tendo algum lugar.

$\mathrm{Na}$ época em que a tatuagem estava banida, os marinheiros preservaram sua prática. Pensando na função da tatuagem para o marinheiro, vemos como uma marca corporal pode funcionar como lugar simbólico. O marinheiro torna-se um errante sem fronteiras e uma demarcação de territórios na vastidão do mar. A tatuagem pode funcionar como uma forma de recorte, de contenção. Desse ponto de vista, essas escarificações são formas de suporte de um lugar. A constituição desse lugar fundamenta-se numa dupla função: de traço e de escrita. A tatuagem vem expressar algo dessa duplicidade. 
O que está em causa na tatuagem tem a ver com algo que nos sustenta na relação a um olhar. Isso que fazemos com o nosso corpo ao oferecê-lo a uma determinada representação. Assim, a tatuagem recorta uma espécie de olhar no próprio corpo: o que se tatua é um traço do Outro. Essa forma de ornamento é oferecida ao outro (parceiro/semelhante), mas busca uma forma de endereçamento ao olhar do Outro. Dessa maneira, é o olhar do Outro que se imprime, que se marca no corpo. Esse é também o princípio da escrita.

Quando a tatuagem surge na adolescência, aparentemente designa um suporte para circulação social do corpo. A produção dessas marcas tem a ver com a constituição de um circuito da pulsão, isto faz com que o nosso corpo seja libidinizado, mas também, fundamentalmente, representado. A libidinização e o suporte representacional (que se constituem em um mesmo movimento) permitem que circulemos socialmente.

No que diz respeito ao registro da pulsão, é importante lembrar duas passagens do trabalho de Lacan. Numa delas, que encontramos no texto sobre a subversão do sujeito (Lacan, 1966), o autor constrói uma metáfora da pulsão como um escravo mensageiro, do tempo antigo, que leva uma mensagem que the foi tatuada no couro cabeludo enquanto ele dormia - sem que ele soubesse -, sendo que ele desconhece o texto, e mesmo que o condena à morte, quando chegar a seu destino. Com essa metáfora, Lacan indica um elo da pulsão com a tatuagem: de como nosso corpo é marcado de traços invisíveis e incompreensíveis, apesar de expressarem materialidades - que buscam o endereço de uma leitura. Podemos entender que as tatuagens dirigem-se a um olhar. Mas aqui encontramos duas determinações: a busca de um lugar no amor do outro, pela busca de uma decifração de traços corporais. Nesse sentido que essa busca de "leitura/decifração" determina um destino. É interessante como, nesse momento lá, entra em jogo a referência à morte.

A outra passagem está contida no seminário sobre os conceitos fundamentais da psicanálise (Lacan, 1964). Ali, Lacan liga a tatuagem com uma função da erótica. Mas desde que essa erótica não é imediatamente apreensivel como normalmente entendemos. Ela se constitui de uma forma muito complexa: desde uma espécie de encarnação do órgão (o corte e a cicatriz dizem de um masoquismo erógeno), até o sítio do sujeito, nesse ser para o Outro, marcando seu lugar entre os semelhantes. Neste último sentido, aproxima-se à impressão do traço unário. Em outro lugar, do mesmo seminário, Lacan comenta que o traço unário se marca como tatuagem - primeiro dos significantes - operando no nível da contagem, instituindo uma diferença que singulariza o lugar do sujeito.

Pelo que foi exposto anteriormente, pode-se perceber que a função ocupada pela tatuagem é sobredeterminada. Pela "encarnação" da libido, ela dá corpo a algo inapreensível, como pode ser o traço primeiro que funda a desnaturação do sujeito, con- 
ferindo, ao mesmo tempo, erotismo a seu funcionamento corporal. Assim, a tatuagem pode colocar em cena - ser um representante daquilo que tem valor totêmico: o que faz com que o corpo e sua representação sejam, ao mesmo tempo, coletivizáveis e singulares.

Num outro trabalho (Costa, 2001), ocupamo-nos da abordagem desses elementos por meio da análise do filme $O$ Livro de Cabeceira, de Peter Greenaway. Esse filme traz uma série de elementos interessantes. Por um lado, a possibilidade de apresentar mundos distintos - situados pela duplicidade masculino/feminino - sustentados por um elemento em comum, que é a escrita. Essa escrita é o que vai tornar o corpo um elemento de circulação. A questão mais interessante, que vai ocupar a personagem central do filme, é que, quando entra o corpo como um elemento de circulação, o pai decai do ato de criador, de pai idealizado, assumindo uma condição de humilhação. Greenaway mostra, pela representação de uma série de simbolismos/metáforas, um momento em que a descoberta do sexual é também a condição em que um pai decai de seu lugar, passando da posição de criador para o de criatura. A experiência dessa passagem se representa como o trauma de descobrir um pai humilhado, submetido a objeto de circulação social. Nesse momento, ela descobre essa face do pai corpóreo, sendo assim que ele decai dessa posição de criador que assina uma obra (símbolo/metáfora expresso num ritual em que o pai escrevia no corpo da menina). Daí, então, ela vai se tornar prisioneira e impossibilitada de expressar qual seria sua relação particular a esse elemento que é a escrita. Ela não consegue mais se livrar da posição decaída do pai.

A série de simbolismos, que o filme traz, leva-nos a pensar nas duas formas de escrita e de marca corporal que a escrita coloca em causa. Por um lado, o que é coletivo, que submete, que constitui uma espécie de universal, que implica a todos e a cada um, inclusive corporalmente, nessa condição de precisar circular socialmente. Tal condição submete o corpo e é também necessário que ela seja suportada corporalmente. É a vertente da menina confrontada com esse campo do masculino, com um valor de circulação universal. Por outro lado, a outra face da escrita, como circulação, apresenta-se nessa posição que está no privado e diz respeito a esse suporte do livro de cabeceira e dos diários. Esse outro elemento, que inclusive faz parte da escrita dos diários na adolescência, refere-se a uma necessidade que está colocada na relação com um resto, como uma impossibilidade de universalizar, de tornar o corpo completamente coletivizável, de sublimar completamente o que fica como resto da operação de representação do corpo. 
Esse resto é conseqüência da socialização. Ele se expressa nos diários, nessa necessidade de ter, de alguma maneira, o suporte da letra, que compõe a condição do privado. É curioso que alguém precise escrever se não for para mostrar. Essa necessidade está colocada na medida em que sempre vai ter um resto ligado ao funcionamento do olhar. Isto implica que este somente funcione a partir de algo velado.

Temos, então, essa forma de constituir a escrita: como, primeiramente, uma escrita do corpo. Vemos como isso se manifesta, em diferentes momentos, na necessidade que temos, na passagem a registros diferentes (da infância para a adolescência, por exemplo), de recuperar uma dimensão da escrita, seja na escrita de diários, ou mesmo na reconstituição dos orifícios na tatuagem. Por virem numa espécie de levantamento do recalque, isso ainda nos impressiona. Essa condição está relacionada com o fato de não conseguirmos passar completamente de um registro ao outro, de não conseguirmos interpretar nosso corpo completamente passando de um registro ao outro, ficando sempre um resto não interpretado, não registrado. É esse resto que se expressa nessa condição da escrita. Isso acontece tanto nos diários como na necessidade de reconstituir um traço no nosso corpo.

As diferentes culturas têm uma espécie de sabedoria implícita de como é que se pode fazer para recuperar uma dimensão de escrita - de amparo e suporte corporais - quando as formas de representação anteriores começam a fracassar. Todas as formas de representação sempre tendem a fracassar, elas pertencem a contextos. Por isso, nunca vamos chegar a uma expressão ideal para suporte de nosso corpo e, também como conseqüência, nunca chegaremos a uma sociedade ideal, ou mesmo a uma representação de homem ou de mulher ideais. É porque não há um suporte natural para nosso corpo e, por outro lado, não há uma assimilação completa da representação de nosso corpo. Por essa razão, estamos sempre fazendo passagens, traduções, interpretações. Temos sempre que inventar possibilidades de inclusão, ou formas diferentes de circulação. Também por essa razão estamos constantemente inventando formas de refazer os orifícios corporais, na medida em que nunca estão completamente recortados.

A tatuagem, por exemplo, contém um elemento de erogenização do corpo: produzir prazer nesse oferecimento ao olhar. No entanto, ela também pode trazer um elemento de insuficiência e tornar-se compulsão. Aquilo que poderia ser suficiente para constituir um lugar no olhar do Outro, que permitisse uma coletivização do corpo, poderá vir a constituir uma compulsão. Essa espécie de insuficiência da marca, do recorte, essa espécie de 
borda sempre necessitando ser refeita, pode constituir compulsão. Talvez isso se coloque em relação à necessidade de tatuar o corpo por inteiro, por exemplo. Na história da tatuagem, encontramos representações de homens que se tatuavam por inteiro. Eles eram expostos, na época da proibição religiosa, quando a tatuagem era uma raridade. Quando os marinheiros descobriram pessoas tatuadas no Haiti, em lugares onde havia culturas que mantiveram a tatuagem, levaram-nas para Londres como espécies raras. Ali elas foram expostas e virou moda. A tatuagem retornou para a cultura ocidental com a queda do valor cristão e do monoteísmo.

É importante pensar-se, na relação ao olhar do Outro, na diferença entre a tatuagem e a maquiagem. Isso que diferencia os lugares, na produção de uma imagem, entre a necessidade de uma marca definitiva e a necessidade da produção de um engano. A maquiagem também tem a constituição do olhar do Outro no corpo. Mas essa condição do olhar não permite a suposição de algo que seria definitivo. Isso que se joga na maquiagem tem mais a ver com a possibilidade de brincar com o engano. Na tatuagem não se brinca com o engano. Constitui uma espécie de necessidade de recortar o olhar no corpo que não tem a ver com o engano, com a máscara, no sentido corriqueiro em que todos nós a produzimos. A tatuagem tem essa necessidade do definitivo e somente secundariamente se coloca em relação ao jogo do engano. Essa condição de erotização traz sua outra face, que é a dor. Temos, nessa experiência, a repetição de algo, definido por Freud, como uma condição erógena primária do masoquismo. Na tatuagem há uma perfuração da derme que joga uma função importante no processo.

Teríamos, também, de pensar na forma particular como se inscreve a tatuagem nas diferentes organizações de laço social. Nossa sociedade é organizada pelo consumo, ela faz com a tatuagem o que ela faz com todo o resto, na medida em que a moda $e$ as insuficiências das marcas nos dirigem. Isso não traz problema ao ato em si, mas à dificuldade particular de cada registro. Assim, torna-se importante diferenciar a qual necessidade responde essa experiência e como ela se inscreve na nossa forma peculiar de coletivização.

Quando se diz que a marca no corpo, de alguma maneira, tenta representar o irrepresentável, isso quer dizer que ela se define pela margem. A margem, a borda, aquilo que resta. As marcas corporais não conseguem ser substituídas completamente pelas representações simbólicas. Se pela tatuagem alguém consegue de alguma maneira se incluir numa espécie de circulação social, para outra pessoa isso pode não ser efetivo. Não é possível uma interpretação genérica do que pode ser a representação de cada um. Os elementos culturais compõem as diferentes formas de interpretação, que variam de acordo com o modo que cada um se orienta no mundo.

A partir de tudo o que foi exposto anteriormente, é possível destacar os principais elementos que situam a tatuagem como um veículo de circulação social. Eles dizem res- 
peito à necessidade de algo que atualize - colocando em ato - a impressão primária das marcas corporais. Essa impressão compõe a reunião de heterogêneos, como podem ser o registro corporal de um símbolo (o sem sentido e abstrato traço unário: primeira impressão simbólica); bem como a impressão enquanto experiência corporal de prazer/desprazer, definida por Freud (1925) como necessária à incorporação de uma representação. Assim, o tatuar-se, na passagem adolescente, vai situar uma forma de repetição dessa impressão primária. Reúne, num mesmo movimento, as precondições para o suporte de nossos referentes. Compõese de elementos híbridos tais como recorte e cicatriz de um órgão/libido; orifício/objeto do olhar; letra/ desenho/traço corporal.

Essas precondições podem ser pensadas como um balizamento, para o estabelecimento de um território, naquilo que pode vir a ser um lugar representacional. Em relação a esse lugar, acompanhamos a transição da passagem do corpo a um lugar de enunciação como eu, pela expressão de um sujeito indeterminado. Isso que é indeterminado aparece na maneira como se costuma enunciar o ato de tatuar. Essa indeterminação é resultante de que o sujeito busca ativamente uma posição passiva, condição própria de um circuito da pulsão. No Brasil, costuma-se dizer "eu me tatuei", apesar de haver a entrega do corpo a um tatuador. Na França, já há um enunciado composto, no se faire faire ("se fazer fazer"). Observamos aí uma composição tatuador/tatuado, em que se perde a delimitação de fronteiras en- tre um e outro. No suporte do tatuador, o sujeito se ausenta de seu corpo e pode gozar como terceiro no acontecimento. Essa é a condição, descoberta por Freud, do erotismo da posição que acontece no masoquismo primário.

Essa condição de erotismo, que se coloca em ato na tatuagem, diz respeito a algo bem mais abrangente. Essa marca que se imprime pela posição de um masoquismo primário retorna na relação a muitos outros elementos. Assim, a dor e humilhação podem vir a se tornar condições eróticas em si mesmas. Isso que é a precondição de nossos recortes corporais pode vir a se tornar condição única e determinante da forma de suporte corporal. Assim, padecimento e mutilação podem tornar-se fins em si mesmos. O que permite um suporte - um limite a essa busca determinante do masoquismo - é sua inserção num pacto amoroso.

De alguma maneira, a entrada na cultura mutila e o mutilar produz detritos, restos impossíveis de representar. Com os restos corporais se produz arte e literatura, que é uma forma de reinscrevê-los na cultura. Muitas vezes fazemos o inverso: interpretamos como detrito o nosso aparente sucesso, o nosso produto maior. Mesmo um filho pode vir a ocupar o lugar de resto. Dentro disso, dor e mutilação - ou o retorno desse masoquismo primário - ocupam lugares variados na forma como cada um se organiza.

A escarificação, como formação de tatuagem, implica uma posição peculiar em relação ao olhar. Para que alguém marque seu corpo dessa 


\section{Dossiê}

maneira, tem de existir uma relação particular à representação do próprio corpo. O que retorna, ali, situa-se como um corpo estrangeiro. De alguma forma algo do corpo não entra na via fálica, algo que diz respeito a esse seu lugar não entra na circulação de um universal fálico. Essa é uma forma de primeiro marcar o corpo, para poder torná-lo objeto de circulação, objeto de representação social.

Se na passagem adolescente essa forma de marcar pode ser suporte de uma singularidade, também temos experiências sociais em que a tatuagem imprime anonimato. Como não lembrar das tatuagens de números, no corpo, realizadas nos campos de concentração? O paradoxal é que um ato, que costumeiramente provoca erotismo e é precondição de singularidade, foi usado para produzir efeitos opostos. Enquanto tatuagem, o que seria para constituir um corpo erotizado, um corpo que circula no coletivo, constituiu-se, na organização nazista, a condição necessária de deserotização, uma maneira de tirar a forma do corpo. O número tatuado, nos campos de concentração, priva o sujeito do suporte do traço unário, fixando o corpo como dejeto nãorepresentável pelo circuito civilizador.

Como saída dessa experiência social, há uma constância de procurar escrever, que é tentar, de alguma maneira, tornar coletivo algo que resiste a esse registro. Temos vários testemunhos autobiográficos de sobreviventes de campos de concentração. Porque se vê que ali se forma uma espécie de trauma que não faz borda. A condição de coletivizar o corpo é a de que ele represente algo que se inscreva no olhar do Outro. A marca corporal constitui algo que faz circular o olhar pelo corpo. Se isso faz borda, é porque, de alguma maneira, alguma coisa se subtraiu ao olhar. Ali, na subtração, foi estabelecida uma marca. É-se olhado por aquilo que não está ali, sendo esse o princípio do amor. Ama-se algo que o outro representa, não sua "natureza". Ama-se, no outro, algo que ele pode vir a representar, situando-se ali o que é inassimilável em relação ao próprio corpo.

REFERÊNCIAS BIBLIOGRÁFICAS

Costa, A (2001). Corpo e Escrita. Relações entre memória e transmissão da experiência. Rio de Janeiro, RJ: Relume Dumará.

Freud, S. (1925). La negación. In Obras Completas. Madrid: Biblioteca Nueva, 1972.

Lacan, J. (1964). O Seminário, Livro XI. Os quatro conceitos fundamentais da psicanálise. Rio de Janeiro, RJ: Zahar.

(1966). Subversão do Sujeito e Dialética do Desejo no Inconsciente Freudiano. In Escritos. Rio de Janeiro, RJ: Zahar.

Wiener, S. (2001). Le tatouage, de la griffe ordinaire à la marque subjective. In Essaim, n² 8, Paris: Érès.

\section{NOTA}

1 Artigo resultante da pesquisa de pós-doutorado desenvolvida na Universidade de Paris 13, subvencionada pela CAPES (Brasil).

Recebido em maio/2002. 